\title{
SIMULAÇÃO DA DISPERSÃO DE POLUENTES NA CAMADA LIMITE PLANETÁRIA UTILIZANDO UM SISTEMA DE MODELOS
}

Jonas C. Carvalho e Gervásio A. Degrazia

Departamento de Física - CCNE

UFSM - Santa Maria, RS -

Domenico Anfossi e Silvia Trini Castelli

Consiglio Nazionale delle Ricerche

Istituto di Cosmo-Geofísica -10133, Turin, Italy.

\section{RESUMO}

O modelo meteorológico RAMS e o modelo de partículas Lagrangeano SPRAY são acoplados para simular o transporte e a difusão de um poluente emitido durante o experimento TRACT, realizado no vale do Reno, na Europa Central. Os resultados das simulações geradas pelo sistema de modelos são avaliados contra dados observacionais medidos durante o experimento TRACT. Análises dos resultados e a aplicação de índices estatísticos mostram que os modelos considerados reproduzem bem o comportamento geral da pluma do poluente, a distribuição temporal e espacial da concentração e a localização do máximo de concentração. 


\begin{abstract}
The meteorological model RAMS and the Lagrangian particle model SPRAY are coupled to simulate the transport and diffusion of tracer released during the project TRACT, realized in the Rhine valley, Central Europe. The simulation results generated by the model system are evaluated against observational data measured in the TRACT experiments. Analysis of the results and the application of statistical indices show that the considered models reproduce well the general behaviour of the contaminant plume, the temporal and spatial distribution of the concentration and the location of the concentration maxima.
\end{abstract}

\title{
1. INTRODUÇÂO
}

A poluição atmosférica é ocasionada por efeitos naturais (por exemplo, emissão de $\mathrm{SO}_{2}$ por um vulcão) ou antropogênicos (por exemplo, emissões industriais e automotivas). Enquanto os níveis de poluição natural podem ser considerados constantes no tempo, os níveis de poluição ocasionada pelo ser humano estão em contínuo aumento. Se sobre a poluição natural não existe, em geral, um controle, ao contrário, sobre a poluição antropogênica pode haver formas de controle.

São muitos os problemas que a poluição do ar, produzida por atividades antropogênicas, ocasiona ao equilíbrio ecológico. Os gases e poeiras abandonados na atmosfera provocam efeitos negativos nas proximidades das fontes (deteriorando a qualidade do ar em regiões urbanas, agrícolas e industriais), a média e longa distâncias (chuva ácida, transporte transfronteiriço) e em escala global (buraco de ozônio).

É importante, portanto, estudar e entender o processo de dispersão de poluentes na atmosfera para prever as possíveis conseqüências do impacto da poluição sobre diversos ecossistemas. No estudo da dispersão 
de poluentes, duas fases devem ser consideradas: observação de campo e modelagem numérica. A primeira consiste em medidas dos valores de concentração e dos principais parâmetros meteorológicos que influenciam a dispersão. A segunda fase consiste no desenvolvimento de modelos para simular numericamente as medidas efetuadas, dando uma interpretação suficientemente correta do fenômeno físico observado. As observações de campo são muitas vezes dificultadas por problemas operacionais e pelos altos custos. Como conseqüência, a modelagem numérica torna-se uma fonte de informação importante para descrever o processo de dispersão na atmosfera.

A modelagem numérica desenvolvida até os dias de hoje pode ser classificada de acordo com vários critérios. A principal subdivisão, de um ponto de vista físico, é feita entre modelos Euleriano e modelos Lagrangeanos. Cada uma destas categorias de modelos de dispersão apresenta vantagens e desvantagens no tratamento do fenômeno atmosférico. A diferença básica entre as aproximações Euleriana e Lagrangeana é que o sistema de referência Euleriano encontra-se fixo em relação a terra, enquanto o sistema de referência Lagrangeano está relacionado com as acelerações de elementos do fluido, os quais mudam de posição continuamente.

Neste trabalho utiliza-se um sistema de modelos computacional para descrever os processos de transporte e difusão de espécies escalares na camada limite planetária (CLP). Para isto, o modelo meteorológico RAMS (Regional Atmospheric Model System) e o modelo de partículas Lagrangeano SPRAY são acoplados para simular a dispersão de um poluente emitido durante o experimento TRACT (Transport of Air Pollutants over Complex Terrain), realizado na região do vale do Reno, na Europa Central. Um objetivo adicional é implementar uma nova parametrização para os parâmetros turbulentos Lagrangeanos (variâncias das velocidades turbulentas e escalas de tempo de descorrelação Lagrangeana), a qual gera valores contínuos para 
todas as condições de estabilidades (estável, instável e neutro) e para todas as alturas na CLP.

Os modelos de partículas Lagrangeanos descrevem 0 movimento de um conjunto de partículas que seguem passivamente o escoamento. As partículas movem-se seguindo os vórtices turbulentos, descrevendo trajetórias aleatórias. Estes modelos são, portanto, estatísticos, ou seja, as grandezas físicas responsáveis pelo deslocamento das partículas são especificadas em termos probabilísticos. A partir da distribuição espacial das partículas em um certo instante de tempo é possível determinar a concentração do poluente emitido. O modelo de partículas Lagrangeano SPRAY é um modelo tridimensional para simular a dispersão de poluentes sobre terreno complexo. O modelo é baseado na equação de Langevin e as quantidades de entrada são o campo de vento e os parâmetros turbulentos. O campo de vento é obtido a partir do modelo meteorológico RAMS. O campo turbulento é obtido através de um programa de interface que acopla os modelos RAMS e SPRAY. Este programa de interface, denominado MIRS (Method of Interface RAMS and SPRAY), obtém os dados meteorológicos a partir do RAMS e fornece as parametrizações da turbulência para o modelo de partículas SPRAY.

Os resultados das simulações geradas pelo sistema de modelos RAMS-MIRS-SPRAY são comparados com dados observacionais medidos durante o experimento TRACT. Índices estatísticos são utilizados para comparar os valores de quantidades previstas pelo modelo RAMS com valores das mesmas quantidades observadas durante o experimento. Dados de concentrações medidos no nível superfície e em altitude são utilizados para avaliar os valores de concentração calculados pelo modelo SPRAY. Os resultados das simulações mostram que o sistema de modelos considerado reproduz bem o comportamento geral da pluma do poluente e a distribuição temporal e espacial da concentração. 
Este trabalho esta dividido em cinco seções. Na segunda seção apresenta-se o sistema de modelos RAMS-MIRS-SPRAY. Na terceira, realiza-se um descrição sobre o experimento TRACT. Na quarta seção são discutidos os resultados. Na quinta seção apresenta-se as conclusões.

\section{O SISTEMA DE MODELOS}

O sistema de modelos é baseado na combinação do modelo atmosférico RAMS (Regional Atmospheric Model System), do código de interface MIRS (Method of Interface RAMS and SPRAY) e do modelo de partículas Lagrangeano SPRAY.

\subsection{O Modelo Meteorológico RAMS}

O RAMS é um modelo de circulação prognóstico desenvolvido na Universidade do Estado do Colorado (Pielke at al., 1992). É baseado na integração das equações diferenciais de conservação da quantidade de movimento, de massa e de energia, com referência a um sistema de coordenadas seguindo o terreno, ou seja, um sistema de coordenadas ideal para simulações em lugares de orografia complexa. O modelo inclui um grande número de opções, as quais podem ser selecionadas pelo usuário. As principais opções compreendem as versões hidrostática e não-hidrostática, aninhamento de grades interativas, grade vertical telescópica, sistema de inicialização pelo esquema de nudging, diferentes opções de esquemas numéricos e de condições de contorno e inúmeras parametrizações físicas. $O$ modelo também é provido de um modelo de solo e vegetação. O modelo RAMS pode simular qualquer situação de escoamento (da microescala até a escala sinótica) e é utilizado por muitos pesquisadores em diferentes aplicações. 


\subsection{O Código de Interface MIRS}

O código de interface MIRS (Trini Castelli e Anfossi, 1997) faz uso de alguns campos de saída do modelo RAMS (velocidade do vento, energia cinética turbulenta, coeficientes de difusão, temperatura potencial, fluxos de momentum e de calor na superfície e topografia) e calcula diversos parâmetros para o modelo SPRAY, não diretamente calculados pelo RAMS. Os parâmetros calculados pelo MIRS compreendem os parâmetros da camada superficial (velocidade de fricção $u_{*}$, escala de temperatura $\theta_{*}$ e o comprimento de Monin-Obukhov $L$ ), a escala de velocidade convectiva $w_{*}$, as variâncias das flutuações de velocidade $\sigma_{i}^{2}$, as escalas de tempo de descorrelação Lagrangeana $\tau_{L_{i}}$, o terceiro e 0 quarto momentos das flutuações de velocidade vertical e a altura da CLP, onde $i=1,2,3$. Depois de ler as saídas do RAMS e de calcular os parâmetros descritos acima, o MIRS escreve num único arquivo, com uma seqüência temporal de interesse, os valores de velocidade do vento, temperatura potencial, turbulência, altura da CLP e topografia, em um formato ideal para ser utilizado pelo modelo SPRAY como informação de ingresso.

Para as variâncias das flutuações de velocidade e para as escalas de tempo de descorrelação Lagrangeana, três esquemas estão disponíveis no MIRS: baseado no campo de energia cinética turbulenta prognosticado do modelo RAMS (Mellor e Yamada, 1982), baseado no traballho de Hanna (1982) e baseado no trabalho de Degrazia et al. (2000). Para o cálculo do terceiro momento da velocidade vertical, utiliza-se a expressão sugerida por Chiba (1978) e para o quarto momento utilizam-se a expressão de Ferrero e Anfossi (1998). Para a altura da CLP, três métodos são considerados: McNider e Pielke (1981), Maryon e Buckland (1994) e Kalthoff et al. (1998). Nos dois primeiros métodos, McNider e Pielke (1981) e Maryon e Buckland (1994), o perfil do número de Richardson gradiente, $R i$, é considerado e a altura onde $R i$ torna-se maior do que um valor crítico, $R i_{c}$, é 14 Rev. Ciência e Natura, Dispersion Process: 9 - 2000. 
escolhida como a altura da CLP. O terceiro método é baseado no trabalho observacional de Kalthoff et al. (1998), realizado a partir de dados coletados durante o experimento TRACT. As observações mostraram que, durante condições de céu claro e fraca subsidência, a altura da camada limite convectiva (CLC), $z_{i}$, segue, aproximadamente, a altura da orografia dentro e fora do vale do Reno.

A implementação das parametrizações de Degrazia et al. (2000) no MIRS representa uma das novidades deste trabalho. Estas parametrizações foram derivadas a partir da teoria de difusão estatística de Taylor e do espectro de energia cinética turbulenta, onde foi suposto uma combinação linear da turbulência mecânica e da turbulência térmica (Frisch,1995). As expressões para as variâncias e para as escalas de descorrelação são:

$$
\begin{gathered}
\sigma_{i}^{2}=\frac{1,06 c_{i}\left(\psi_{\varepsilon} \frac{z}{z_{i}}\right)^{2 / 3} w_{*}^{2}}{\left[\left(f_{m}^{*}\right)_{i}^{c}\right]^{2 / 3}}+\frac{2,32 c_{i} \phi_{\varepsilon}^{2 / 3} u_{*}^{2}}{\left[\left(f_{m}^{*}\right)_{i}^{n+e}\right]^{2 / 3}} \\
\mathrm{e} \tau_{L i}=\frac{z}{\sqrt{c_{i}}}\left\{\frac{0,14\left(\frac{-\bar{L}}{z_{i}} \frac{z_{i}}{-L}\right)^{1 / 2}}{\left[\left(f_{m}^{*}\right)_{i}^{c}\right]^{2 / 3} w_{*}\left(\psi_{\varepsilon}^{c} \frac{z}{z_{i}}\right)^{1 / 3}}+\frac{0,059}{\left[\left(f_{m}^{*}\right)_{i}^{n+e}\right]^{2 / 3} \phi_{\varepsilon}^{1 / 3} u_{*}}\right\},
\end{gathered}
$$

onde $\psi_{\varepsilon}$ e $\phi_{\varepsilon}$ são as taxas de dissipação adimensionais, $\left(f_{m}^{*}\right)_{i}^{c}$ é a frequência reduzida do pico do espectro convectivo, $\left(f_{m}^{*}\right)_{i}^{n+e}$ é a freqüência reduzida do pico do espectro neutro ou estável, $-\bar{L} / z_{i}$ é um parâmetro de estabilidade médio para a CLC e $c_{i}=\alpha_{i} \alpha_{u}(2 \pi \kappa)$, com $\alpha_{i}=1,4 / 3,4 / 3$ para as componentes $u, v$ e $w$, respectivamente, e $\alpha_{u}=0,5 \pm 0,05$. Estas parametrizações geram valores contínuos em todas as 
elevações $\left(z_{0} \leq z \leq h_{e}, h_{n}, z_{i}\right)$ e em todas as condições de estabilidade $(-\infty<L<\infty)$, onde $z_{0}$ é o comprimento de rugosidade, $h_{e}$ é a a altura da camada limite estável (CLE) e $h_{n}$ representa a altura da camada limite neutra $(\mathrm{CLN})$.

\subsection{O Modelo Lagrangeano SPRAY}

O modelo SPRAY (Tinarelli et al., 2000) é um modelo de partículas Lagrangeano e foi desenvolvido para estudar a dispersão de poluentes sobre terreno complexo, emitidos a partir de qualquer tipo de fonte. SPRAY é baseado na forma tridimensional da equação de Langevin para a velocidade aleatória (Thomson, 1987). A velocidade e a posição das partículas são obtidas pelas seguintes equações:

$$
d u_{i}=a_{i}(\boldsymbol{x}, \boldsymbol{u}, t) d t+b_{i j}(\boldsymbol{x}, \boldsymbol{u}, t) d W_{j}(t)
$$

e

$$
d \boldsymbol{x}=(\boldsymbol{U}+\boldsymbol{u}) d t,
$$

onde $i, j=1,2,3, \boldsymbol{x}$ é o vetor deslocamento, $\boldsymbol{U}$ é o vetor velocidade média do vento, $\boldsymbol{u}$ é o vetor velocidade Lagrangeana, $a_{i}(\boldsymbol{x}, \boldsymbol{u}, t) d t$ é um termo determinístico, $b_{i j}(\boldsymbol{x}, \boldsymbol{u}, t) d W_{i}(t)$ é um termo estocástico e a quantidade $d W_{j}(t)$ é o processo incremental de Wiener. O coeficiente $a_{i}(\boldsymbol{x}, \boldsymbol{u}, t)$ depende de uma função densidade de probabilidade Euleriana (PDF) da velocidade turbulenta e deve ser determinado a partir da equação de FokkerPlank. Nas duas direções horizontais a PDF é assumida ser Gaussiana. Na direção vertical, devido a não-uniformidade das condições turbulentas e/ou convecção, a PDF é não-Gaussiana. Neste caso, duas diferentes aproximações para a PDF podem ser adotadas a fim de calcular a equação de Fokker-Planck: uma bi-Gaussiana, truncada na terceira ordem, e uma Gram-Charlier (Anfossi et al., 1997), truncada na terceira ou quarta ordens. O coeficiente de difusão $b_{i j}(\boldsymbol{x}, \boldsymbol{u}, t)$ é obtido a partir da função de estrutura 
Lagrangeana e está relacionado à constante de Kolmogorov, $C_{0}$, para o subintervalo inercial. No modelo SPRAY é possível escolher entre um passo no tempo constante ou um variável. O modelo também pode levar em conta o plume rise, se necessário.

\section{O EXPERIMENTO TRACT}

O experimento TRACT (TRAnsport of Air Pollutants over Complex Terrain) foi um subprojeto do EUROTRACT, o qual é um programa de pesquisa que tem por objetivo investigar o transporte e a transformação química de poluentes na troposfera sobre a Europa. O experimento TRACT, realizado entre os dias 07 e 23 de Setembro de 1992, representou um dos principais programas de campo do EUROTRACT. O experimento visou os processos atmosféricos de transporte e difusão de poluentes, os quais são forçados por influências térmicas e dinâmicas devido à não-homogeneidade do terreno (Zimmermann, 1995).

\section{1. Área de Investigação e Estruturas Orográficas}

A área principal de investigação do TRACT está situada na Europa Central e inclui o sudoeste da Alemanha, o leste da França e o norte da Suíça (Figura 1). A área estende-se a partir de $47^{\circ} \mathrm{N}$ a $50^{\circ} \mathrm{N}$ em latitude e a partir de $6,5^{\circ} \mathrm{E}$ a $10^{\circ} \mathrm{E}$ em longitude, ou seja, aproximadamente $300 \mathrm{~km}^{2}$. As elevações do terreno na região do TRACT variam de 100 a $1500 \mathrm{~m}$ acima do nível do mar. As estruturas orográficas mais importantes que influenciam o escoamento são vales (Reno, Swiss Midland, Kraichgau, Neckar) e montanhas (Vosges, Floresta Negra, Schwabische Alb, Swiss Jura). O vale do Reno estende-se entre as montanhas Vosges, a oeste, e Floresta Negra, a leste. A orientação do vale do Reno é de sudoeste para nordeste e tem Rev. Ciência e Natura, Dispersion Process: 9 - 2000. 
largura média de aproximadamente $40 \mathrm{~km}$ (ver Figuras 4 e 5). $\mathrm{Na}$ área do experimento TRACT, diferentes formas de vales e montanhas, com escalas de poucas centenas de metros até vários quilômetros, conduzem ao aquecimento diferenciado da superfície da terra e circulações secundárias são geradas por esta troca de energia não-homogênea.

\subsection{Tipos de Medidas e Experimento de Emissão}

No transcorrer da campanha TRACT fizeram-se três períodos de medidas intensivas (PMl's), durante os quais a totalidade dos equipamentos disponíveis coletaram dados por pelo menos 24 horas consecutivas. Um número muito grande de diferentes tipos de medições foram efetuados. Sistemas de observações de ar e superfície foram utilizados: 10 aviões, 18 estações de radiosondas, 1 estação exclusivamente para balões piloto, 7 balões cativos, 6 estações com sodars, 1 estação com lidar, 1 estação com rass, estações de balanço de energia, estações de deposição, estações meteorológicas e estações químicas. Além destes, dados a partir de redes operacionais (meteorológicas e químicas) foram adicionados aos dados coletados no TRACT. Durante o experimento o uso do solo também foi determinado. Cidades, áreas agrícolas, florestas e campos são os principais tipos de uso do solo na região do vale do Reno.

Medições de concentração foram realizadas no $2^{\circ}$ PMI (16 - 17 de Setembro). A emissão ocorreu de uma fonte com altura de $8 \mathrm{~m}$ na localização de Sasbach $\left(48,65^{\circ} \mathrm{N}\right.$; $\left.08,088^{\circ} \mathrm{E}\right)$, no vale do Reno, por aproximadamente 3 horas (das 05:02 UTC às 07:58 UTC). O traçador utilizado foi o perfluordimetilcicloexano $(\mathrm{PDCH})-\mathrm{C}_{8} \mathrm{~F}_{16}$ e a taxa de emissão foi de $5 \mathrm{~g} / \mathrm{s}$. Vinte estações de amostragem de concentração foram posicionadas nas proximidades da fonte. Das 20 estações, somente 10 registraram valores de concentração. A localização destas 10 estações é apresentada na Figura 2 e na Tabela 1.

Rev. Ciência e Natura, Dispersion Process: 9 - 2000. 


\begin{tabular}{ccccc}
\hline $\begin{array}{c}\text { estação de } \\
\text { emostragem }\end{array}$ & $\begin{array}{c}\text { código da } \\
\text { estação }\end{array}$ & $\begin{array}{c}\text { longitude } \\
\text { (graus) }\end{array}$ & $\begin{array}{c}\text { latitude } \\
\text { (graus) }\end{array}$ & $\begin{array}{c}\text { distância da } \\
\text { fonte }(\mathrm{m})\end{array}$ \\
\hline Oberweier & 1 & 8,120 & 48,691 & 5207 \\
Mülhofen & 4 & 8,152 & 48,750 & 12030 \\
Baden-Oos & 6 & 8,183 & 48,794 & 17459 \\
La Wantzenau & 21 & 7,833 & 48,659 & 18749 \\
Pfettisheim & 22 & 7,648 & 48,660 & 32348 \\
Stefans-Berg & 23 & 7,497 & 48,641 & 44094 \\
Sasbach & 32 & 8,096 & 48,647 & 334 \\
Birkenhöf & 34 & 8,138 & 48,607 & 5962 \\
Breitenbrunnen & 37 & 8,183 & 48,621 & 7681 \\
Hornisgrinde & 38 & 8,211 & 48,611 & 10061 \\
\hline
\end{tabular}

Tabela 1 - Localização das estações de amostragem de concentração.

A Tabela 2 apresenta a relação de estações de amostragem que mediram concentração e os horários em que as medições foram feitas. Examinando a Tabela 2 e a Figura 2, pode-se determinar a trajetória da pluma observada durante o experimento de emissão. Nota-se que o traçador tomou a direção de sudoeste para nordeste, paralelo ao vale do Reno (às 6:00 UTC havia atingido a estação 32 , às $6: 30$ UTC a estação 1 , às 7:30 UTC a estação 4 e às 8:00 UTC a estação 6). Lembrando que às 7:58 UTC terminava a emissão. Nesta primeira fase, sendo provavelmente a pluma ainda muito estreita sobre o plano horizontal e sendo todos os amostradores alinhados ao longo da mesma direção (faltando assim uma linha de 
amostradores colocada em arco ortogonalmente a pluma), a probabilidade de obter uma boa simulação com o modelo de dispersão é baixa. Basta apenas um pequeno erro (da ordem de 5-10 graus) na direção do vento, simulada pelo modelo meteorológico RAMS, para provocar um desvio da pluma em relação aos amostradores. Em seguida, a pluma foi transportada para reaparecer às 10:00 UTC nos amostradores 32 e 37 sem, entretanto, movimentar-se sobre os amostradores 33, 35 e 36 (não aparecem na Figura 2 ), que foram interpostos entre os dois primeiros. Deve-se, portanto, supor uma mudança de direção do vento que transportou o traçador para trás, provavelmente separado em vários puffs, que seguiram percursos diversos. Somente às 11:00 UTC o amostrador 34 registrou concentração, às 12:00 UTC os amostradores 32 e 34, às 13:00 UTC o amostrador 32 e às 14:00 os amostradores 21, 22 e 38. Duas horas depois, às 16:00 UTC, valores de concentração foram registrados pelo amostrador 23, e às 17:00 UTC, 12 horas depois do início do abandono, valores foram registrados pelo amostrador 21. Observa-se, portanto, que os vários puffs tomaram caminhos completamente diferentes, visto que os amostradores 21,22 e 23 estão distantes dos outros amostradores e em posição oposta em relação a fonte de emissão. Um fato inexplicável é o valor da concentração relativamente elevado encontrado às 12:00 UTC no amostrador 32. Pode-se pensar que, no início da dispersão, um puff do traçador permaneceu aprisionado muito próximo ao solo em uma zona de estagnação do vento. O mesmo permaneceu 'concentrado', para depois ser transportado por um aumento local da velocidade do vento que o colocou em movimento e depois sucessivamente o dispersou. 


\begin{tabular}{cccc}
\hline $\begin{array}{c}\text { Estação de } \\
\text { amostragem }\end{array}$ & $\begin{array}{c}\text { código da } \\
\text { estação }\end{array}$ & hora (UTC) & $\begin{array}{c}\text { concentração } \\
\text { observada }\left(\mu \mathrm{g} / \mathrm{m}^{3}\right)\end{array}$ \\
\hline Sasbach & 32 & $5: 30-6: 00$ & 0,0321 \\
Oberweier & 1 & $6: 00-6: 30$ & 3,0276 \\
Sasbach & 32 & $6.30-7: 00$ & 0,0241 \\
Oberweier & 1 & $7: 00-7: 30$ & 1,3202 \\
Mülhofen & 4 & $7: 00-7.30$ & 0,0325 \\
Baden-Oos & 6 & $7: 30-8: 00$ & 0,0034 \\
Oberweier & 1 & $8: 00-8: 30$ & 0,0196 \\
Sasbach & 32 & $9: 30-10: 00$ & 0,0013 \\
Breitenbrunnen & 37 & $9: 30-10: 00$ & 0,0020 \\
Birkenhöf & 34 & $10: 30-11: 00$ & 0,0018 \\
Sasbach & 32 & $11: 30-12: 00$ & 0,0086 \\
Birkenhöf & 34 & $11: 30-12: 00$ & 0,0014 \\
Stefans-Berg & 23 & $10: 30-11: 00$ & 0,0023 \\
Sasbach & 32 & $12: 30-13: 00$ & 0,0013 \\
La Wantzenau & 21 & $13: 30-14: 00$ & 0,0029 \\
Pfettisheim & 22 & $13: 30-14: 00$ & 0,0086 \\
Hornisgrinde & 38 & $13: 30-14: 00$ & 0,0029 \\
Stefans-Berg & 23 & $15: 30-16: 00$ & 0,0023 \\
La Wantzenau & 21 & $16: 30-17: 00$ & 0,0020 \\
\hline
\end{tabular}

Tabela 2 - Horários e valores de concentração observados pelas estações de amostragem durante o experimento de concentração.

\subsection{Situação do Tempo}

O principal objetivo do experimento TRACT foi estudar a dispersão de poluentes do ar sob condições convectivas. Portanto, os períodos de medidas intensivas (PMI's) foram escolhidos quando a área do experimento fosse influenciada por sistemas de alta pressão. A situação do 
tempo durante o $2^{\circ} \mathrm{PMI}$ foi caracterizada por um sistema de alta pressão movendo-se para leste sobre a área do experimento. No dia 16 de setembro, depois do desaparecimento de sinais de nevoeiro em algumas regiões, o dia foi ensolarado. Os ventos dentro da CLP e acima sopraram de oeste noroeste durante o dia. Ao anoitecer, os ventos na superfície passaram a soprar de nordeste quando o centro de alta pressão moveu-se para o norte da área do TRACT. No dia 17 de setembro, parte do vale do Reno foi coberta por nevoeiro, permanecendo assim até o meio-dia. Como conseqüência do movimento para leste do sistema de alta pressão, o escoamento próximo a superfície ocorreu de leste durante este dia. Acima da CLP, o ventos sopraram de oeste - noroeste, como no dia anterior.

\section{RESULTADOS}

\subsection{Configuração do Modelo RAMS}

A simulação com o modelo RAMS foi realizada com três grades aninhadas (Figura 3), sendo a maior (grade 1) com $20 \times 20$ pontos de grade e resolução horizontal de $16 \mathrm{~km}$, a intermediária (grade 2) com $38 \times 38$ pontos e resolução de $4 \mathrm{~km}$ e a menor (grade 3) com $62 \times 62$ pontos e resolução de $1 \mathrm{~km}$. Quarenta níveis verticais foram utilizados em cada uma das grades, com um espaçamento de $50 \mathrm{~m}$ junto a superfície, estendendo-se com uma razão para o 'stretching' vertical de 1,2 até a altura de $500 \mathrm{~m}$. A partir de 500 $\mathrm{m}$ o espaçamento foi mantido constante com valor de $500 \mathrm{~m}$, alcançando o topo do domínio em $15 \mathrm{~km}$. Os passos no tempo nas grades 1,2 e 3 foram de $30 \mathrm{~s}, 10 \mathrm{~s}$ e $3,3 \mathrm{~s}$, respectivamente. A simulação teve início à 00 UTC do dia 15/09 (24 horas antes do início do $2^{\circ} \mathrm{PMI}$ ) e terminou à 00 UTC do dia 18/09, compreendendo um total de 72 horas. O RAMS foi inicializado com dados de reanálise do ECMWF ( $0,5^{\circ}$ latitude/longitude). Estes dados foram analisados 
sobre superfícies isentrópicas e depois interpolados para a grade do modelo. Os dados de inicialização foram informados ao modelo a cada seis horas através do esquema de nudging nos limites laterais da grade maior. Informações sobre o landuse (15" latitude/longitude) e sobre a topografia (30" latitude/longitude) da região também foram fornecidas ao modelo. As Figuras 4 a-c mostram os detalhes da orografia da região para as grades de simulação 1,2 e 3 , respectivamente. Para o modelo de solo, foram considerados sete níveis no interior do solo, com o nível mais profundo em $1,5 \mathrm{~m}$. Valores iniciais de umidade e temperatura no solo foram obtidos a partir de informações do ECMWF para o período do experimento TRACT. O RAMS foi utilizado em sua versão não-hidrostática com a parametrização de Mellor e Yamada (1982) para turbulência. Considerou-se que a umidade atmosférica esteve presente somente na forma de vapor d'água.

\subsection{Avaliação do Modelo RAMS}

Antes de utilizar os campos simulados pelo modelo RAMS como dados de entrada no modelo SPRAY, procedeu-se a uma avaliação dos resultados do RAMS através dos seguintes índices estatísticos:

fractional bias ( $\mathrm{fb}$ )

$$
\begin{aligned}
& f b=2 \frac{\bar{\chi}_{o}-\bar{\chi}_{p}}{\bar{\chi}_{o}+\bar{\chi}_{p}}, \quad \text { (para os escalares e para o módulo do vetor } \\
& \text { velocidade do vento) }
\end{aligned}
$$

root-mean-square error (rmse)

$$
\text { rmse }=\left[\frac{1}{N} \sum\left(\chi_{o}-\chi_{p}\right)^{2}\right]^{1 / 2}, \quad \text { (para os escalares) }
$$


e

root-mean-square vector error (rmsve)

rmsve $=\left\{\frac{1}{N} \sum\left[\left(u_{o}-u_{p}\right)^{2}+\left(v_{o}-v_{p}\right)^{2}\right]\right\}^{1 / 2}, \quad$ (para as componentes da velocidade Cox et al., 1998)

onde $\chi$ representa a quantidade analisada, o índice "o" representa os valores observados e o índice " $p$ " os valores previstos pelo modelo. As médias nos índices estatísticos são médias no tempo, considerando valores separados pelo intervalo de uma hora. Valores positivos de $f b$ indicam que os valores previstos tendem a subestimar os valores observados enquanto valores negativos indicam que os valores previstos tendem a superestimar os valores observados. O rmse e o rmsve representam o erro quadrático dos valores previstos em relação aos valores observados. Quanto mais próximo de zero for o fb e quanto menor forem o rmse e o rmsve, melhor é o resultado. Dados observados em 15 estações de superfície e em 15 estações de radiosondagem estavam disponíveis (Figura 5). Por uma questão de síntese, serão apresentados os resultados da avaliação referentes a algumas poucas estações somente.

A Tabela 3 apresenta os valores dos índices estatísticos considerando valores observados e simulados nas localizações das estações de superfície Colmar-Meyenheim (S3), Guettingeen (S4), Karlsruhe (S5), Muehlacker (S7), Sinsheim (S10), Strassburg (S11) e Stoetten (S14). ColmarMeyenheim, Karlsruhe e Strassburg localizam-se dentro do vale do Reno, Muehlacker e Sinsheim localizam-se no vale Kraichgau, e Guettingeen e Stoetten estão sobre montanhas. Os índices são calculados para as seguintes variáveis: componentes da velocidade do vento $(u, v)$, módulo da velocidade do vento $(V)$, temperatura do ar $(T)$ e umidade específica $(q)$. 


\begin{tabular}{|c|c|c|c|c|c|c|c|c|c|}
\hline estação & $\begin{array}{c}\text { lat. } \\
\text { (graus) }\end{array}$ & $\begin{array}{c}\text { lon. } \\
\text { (graus) }\end{array}$ & $\begin{array}{c}\text { altura } \\
(\mathrm{m} \text { asl) }\end{array}$ & $\begin{array}{c}r m s v e \\
(u, v)\end{array}$ & $\begin{array}{c}f b \\
(V)\end{array}$ & $\begin{array}{c}r m s e \\
(T)\end{array}$ & $\begin{array}{c}f b \\
(T)\end{array}$ & $\begin{array}{c}r m s e \\
(q)\end{array}$ & $\begin{array}{c}f b \\
(q)\end{array}$ \\
\hline$S 3$ & 47,92 & 7,40 & 209 & 1,48 & 0,30 & 4,90 & $-0,007$ & 1,02 & 0,04 \\
\hline$S 4$ & 47,60 & 9,28 & 440 & 3,25 & 0,80 & 3,71 & $-0,14$ & 1,81 & 0,01 \\
\hline$S 5$ & 49,03 & 8,36 & 112 & 1,27 & $-0,02$ & 2,03 & $-0,004$ & 1,02 & $-0,08$ \\
\hline$S 7$ & 48,96 & 8,86 & 244 & 1,46 & 0,15 & 4,42 & $-0,14$ & 2,03 & $-0,15$ \\
\hline$S 10$ & 49,25 & 8,88 & 169 & 1,47 & $-0,16$ & 2,95 & $-0,087$ & 1,28 & $-0,08$ \\
\hline$S 11$ & 48,55 & 7,63 & 150 & 1,61 & 0,26 & 4,55 & $-0,011$ & 1,88 & $-0,14$ \\
\hline$S 14$ & 48,66 & 9,86 & 734 & 2,12 & 0,64 & 2,35 & $-0,006$ & 0,89 & $-0,02$ \\
\hline
\end{tabular}

Tabela 3 - Resultados dos índices estatísticos a partir do confronto entre valores simulados e valores observados nas estações de superfície.

A Figura 6 apresenta a evolução no tempo dos mesmos índices estatísticos para as estações de radiosondagem Bruchsal (R2) (lat./lon.: 49,13/8,56 e altura: $110 \mathrm{~m}$ asl), Musbach (R9) (lat./lon.: 48,50/8,48 e altura: 695 m asl) e Oberbronn (R11) Oberbronn (lat./lon.: 48,94/7,61 e altura: 274 m). As estações Bruchsal e Oberbronn estão situadas dentro do vale do Reno e a estação Musbach está situada sobre a montanha Floresta Negra. Os índices são obtidos para as seguintes variáveis: componentes da velocidade do vento $(u, v)$, módulo da velocidade do vento $(V)$, temperatura do potencial $(\theta)$ e umidade específica $(q)$. Pode-se notar pelos valores dos índices estatísticos que, tanto para a análise em superfície quanto para a análise em altitude, a simulação realizada com o modelo RAMS é satisfatória.

A Figura 7 mostra uma comparação entre as séries no tempo observadas e as séries obtidas pela simulação para a localização da estação de superfície de Sinsheim (S10). As seguintes variáveis são consideradas: módulo da velocidade do vento $(V)$, direção do vento $(d d)$, temperatura do ar $(T)$ e umidade específica $(q)$. Os resultados de velocidade do vento e Rev. Ciência e Natura, Dispersion Process: 9 - 2000. 
temperatura são satisfatórios. O resultado para a umidade específica não é bom e isto pode estar relacionado à escolha dos valores iniciais de umidade no solo. A informação correta dos valores iniciais de umidade no solo é muito importante, pois afeta diretamente o balanço de energia na superfície e os valores do fluxo de calor sensível. A Figura 8 mostra uma comparação entre os perfis observados e os perfis simulados pelo modelo para a localização da estação de radiosondagem Musbach (R9). A comparação é feita para o horário das 12 UTC do dia 16/09. As seguintes variáveis são consideradas: módulo da velocidade do vento $(V)$, direção do vento $(d d)$, temperatura potencial $(\theta)$ e umidade específica $(q)$. Examinando os gráficos nota-se que a qualidade das simulações obtidas com o modelo RAMS é muito boa. Comparações considerando outras estações apresentam resultados semelhantes.

\subsection{Configuração do Modelo SPRAY}

No modelo SPRAY, o cálculo da concentração é feito através da contagem do número de partículas encontradas nos volumes imaginários (células) do domínio de concentração. Os domínios para o cálculo da concentração coincidem com as grades de simulação do modelo meteorológico. No nível junto à superfície, as dimensões das células eram de $500 \times 500 \times 50 \mathrm{~m}$. Acima do primeiro nível, foi feita uma amplificação da dimensão vertical das células até alcançar o último nível da grade de concentração, localizado em $2000 \mathrm{~m}$. O passo de integração foi mantido em 5 s. Todas as parametrizações disponíveis no código de interface MIRS foram testadas. Durante o período de emissão, 100 partículas foram liberadas por passo de tempo. A simulação tive início às 05:02 UTC e foi conduzida até às 09:00 UTC para a grade 3 , até às 10:00 UTC para a grade 2 e até às 18:00 UTC para a grade 1. 


\subsection{Simulação do Experimento de Concentração}

As Tabelas $4 \mathrm{a}-\mathrm{c}$ mostram o confronto entre os valores de concentração no nível da superfície observados e os valores de concentração simulados nas grades 1,2 e 3 , respectivamente. Além dos valores de concentração, as tabelas também mostram o número do amostrador e a respectiva hora de amostragem. Os resultados para a grade de concentração 3 são obtidos entre 5:30 UTC e 08:00 UTC. Depois das 08:00 UTC, poucas partículas encontram-se no domínio e valores de concentração não são mais registrados. De todos os resultados, aqueles que se aproximam mais dos valores observados são os obtidos com as parametrizações Hanna (1982) e Degrazia et al. (2000), independente do método utilizado para determinar a altura da CLP. Para a grade 2, valores de concentração são registrados somente até às 8:30 UTC. Um pouco diferente do que ocorre na grade 3 , os resultados obtidos com a parametrização ECT também são comparáveis aos demais. $\mathrm{Na}$ grade 1 , os melhores resultados são aqueles obtidos com a parametrização de Degrazia et al. (2000) em combinação com a altura da CLP determinada por Maryon e Buckland (1994)e também com as parametrizações Hanna (1982) e Degrazia et al. (2000) em combinação com a determinação da altura da CLP de Kalthoff et al. (1998).

As Figuras $9 \mathrm{a}-\mathrm{d}$ apresentam uma seqüência temporal das posições das partículas. Nas figuras é mostrado também o campo de vento simulado na altura de $10 \mathrm{~m}$. Esta seqüência é obtida utilizando as opções de Kalthoff et al. (1998) para a altura da CLP e Degrazia et al. (2000) para turbulência. As distâncias nos eixos $x$ e $y$ estão em quilômetros e são obtidas em relação às coordenadas absolutas $x=0$ (meridiano de Grenwich) e $y=0$ (equador). Os gráficos se referem aos horários de 06, 08, 12 e 16 UTC do dia $16 / 09$.

Examinando a seqüência de figuras e baseando-se na análise realizada na seção 3.2 (Figura 2 e Tabela 2), é possível notar uma 


\begin{tabular}{|c|c|c|c|c|c|c|c|c|c|c|}
\hline & & & \multicolumn{3}{|c|}{ McNider and Pielke } & \multicolumn{2}{c|}{ Maryon and Buckland } & \multicolumn{2}{c|}{ Kalthoff et al. } \\
\hline hora (UTC) & $\begin{array}{c}\text { núm. } \\
\text { amost. }\end{array}$ & obs. & $\begin{array}{c}\text { ECT }- \\
\text { RAMS }\end{array}$ & Hanna & $\begin{array}{c}\text { Degrazia } \\
\text { et al. }\end{array}$ & $\begin{array}{c}\text { ECT }- \\
\text { RAMS }\end{array}$ & Hanna & $\begin{array}{c}\text { Degrazia } \\
\text { et al. }\end{array}$ & $\begin{array}{c}\text { Hanna } \\
\text { Degrazia } \\
\text { et al. }\end{array}$ \\
\hline $5: 30-6: 00$ & 32 & 0,0321 & 0 & 0,0095 & 0,0031 & 0 & 0,0349 & 0,0031 & 0,0254 & 0 \\
\hline $6: 00-6: 30$ & 1 & 3,0276 & 0,6302 & 1,1955 & 1,3376 & 0,6533 & 1,3111 & 1,6388 & 0,9317 & 1,5293 \\
\hline $6: 30-7: 00$ & 32 & 0,0241 & 0 & 0,3272 & 0,0222 & 0 & 0,8991 & 0,1112 & 0,6958 & 0,0857 \\
\hline $7: 00-7: 30$ & 1 & 1,3202 & 0,0638 & 0,2869 & 0,3747 & 0,0601 & 0,3338 & 0,3809 & 0,3763 & 0,4373 \\
\hline $7: 00-7: 30$ & 4 & 0,0325 & 0,0627 & 0,3111 & 0,3519 & 0,0289 & 0,1748 & 0,2095 & 0,0617 & 0,0614 \\
\hline $7: 30-8: 00$ & 6 & 0,0034 & 0,0091 & 0,1884 & 0,1632 & 0,0048 & 0,0643 & 0,0785 & 0 & 0,0036 \\
\hline
\end{tabular}

Tabela 4a - Valores de concentração observados durante o experimento TRACT e simulados pelo sistema de modelos RAMS-MIRS-SPRAY na grade 3.

\begin{tabular}{|c|c|c|c|c|c|c|c|c|c|c|}
\hline & & & \multicolumn{3}{|c|}{ McNider and Pielke } & \multicolumn{2}{c|}{ Maryon and Buckland } & \multicolumn{2}{c|}{ Kalthoff et al. } \\
\hline hora (UTC) & $\begin{array}{c}\text { núm. } \\
\text { amost. }\end{array}$ & obs. & $\begin{array}{c}\text { ECT - } \\
\text { RAMS }\end{array}$ & Hanna & $\begin{array}{c}\text { Degrazia } \\
\text { et al. }\end{array}$ & $\begin{array}{c}\text { ECT }- \\
\text { RAMS }\end{array}$ & Hanna & $\begin{array}{c}\text { Degrazia } \\
\text { et al. }\end{array}$ & $\begin{array}{c}\text { Hanna } \\
\text { Degrazia } \\
\text { et al. }\end{array}$ \\
\hline $5: 30-6: 00$ & 32 & 0,0321 & 0,0589 & 0 & 0 & 0,0234 & 0 & 0 & 0 & 0 \\
\hline $6: 00-6: 30$ & 1 & 3,0276 & 3,8201 & 2,8186 & 3,0649 & 3,6611 & 2,9737 & 3,2433 & 2,5729 & 3,3490 \\
\hline $6: 30-7: 00$ & 32 & 0,0241 & 0 & 0,0108 & 0 & 0,0036 & 0,1117 & 0,0074 & 0,1226 & 0,0144 \\
\hline $7: 00-7: 30$ & 1 & 1,3202 & 0,4630 & 0,1479 & 0,1580 & 0,5176 & 0,3492 & 0,3106 & 0,4528 & 0,6057 \\
\hline $7: 00-7: 30$ & 4 & 0,0325 & 0,0468 & 0,0097 & 0,0281 & 0,0423 & 0,0067 & 0,0196 & 0,0224 & 0,0344 \\
\hline $7: 30-8: 00$ & 6 & 0,0034 & 0,0067 & 0,0253 & 0,0656 & 0,0064 & 0,0645 & 0,0986 & 0,0076 & 0,0099 \\
\hline $8: 00-8: 30$ & 1 & 0,0196 & 0,0086 & 0 & 0,0036 & 0,0078 & 0,0028 & 0 & 0 & 0 \\
\hline
\end{tabular}

Tabela 8b - Como na tabela $12.6 \mathbf{a}$, mas para a grade 2 . 


\begin{tabular}{|c|c|c|c|c|c|c|c|c|c|c|}
\hline & & & \multicolumn{3}{|c|}{ McNider and Pielke } & \multicolumn{2}{c|}{ Maryon and Buckland } & \multicolumn{2}{c|}{ Kalthoff et al. } \\
\hline hora (UTC) & $\begin{array}{c}\text { núm. } \\
\text { amost. }\end{array}$ & obs. & $\begin{array}{c}\text { ECT }- \\
\text { RAMS }\end{array}$ & Hanna & $\begin{array}{c}\text { Degrazia } \\
\text { et al. }\end{array}$ & $\begin{array}{c}\text { ECT }- \\
\text { RAMS }\end{array}$ & Hanna & $\begin{array}{c}\text { Degrazia } \\
\text { et al. }\end{array}$ & $\begin{array}{c}\text { Hanna } \\
\text { Degrazia } \\
\text { et al. }\end{array}$ \\
\hline $5: 30-6: 00$ & 32 & 0,0321 & 0,0026 & 0,0046 & 0,0008 & 0,0068 & 0,0080 & 0,0002 & 0,0405 & 0,0011 \\
\hline $6: 00-6: 30$ & 1 & 3,0276 & 8,7116 & 2,1669 & 1,6005 & 8,6340 & 2,1687 & 1,6356 & 2,2660 & 1,5473 \\
\hline $6: 30-7: 00$ & 32 & 0,0241 & 0,0020 & 0,0077 & 0,0070 & 0,0033 & 0,0171 & 0,0103 & 0,0701 & 0,0200 \\
\hline $7: 00-7: 30$ & 1 & 1,3202 & 3,0485 & 0,1341 & 0,1047 & 3,1284 & 0,1605 & 0,1094 & 0,2304 & 0,2545 \\
\hline $7: 00-7: 30$ & 4 & 0,0325 & 0,0949 & 0 & 0,0010 & 0,0901 & 0 & 0,0012 & 0,0026 & 0,0046 \\
\hline $7: 30-8: 00$ & 6 & 0,0034 & 0,0097 & 0 & 0,0008 & 0,0089 & 0 & $4 \times 10^{-5}$ & 0,0114 & 0,0121 \\
\hline $8: 00-8: 30$ & 1 & 0,0196 & 0,0011 & 0 & 0,0003 & 0,0003 & 0,0090 & 0,0013 & 0,0088 & 0,0051 \\
\hline $9: 30-10: 00$ & 32 & 0,0012 & 0 & 0 & 0 & 0 & 0 & 0 & 0,0005 & 0 \\
\hline $9: 30-10: 00$ & 37 & 0,0019 & 0 & 0 & 0 & 0 & 0 & $5 \times 10^{-6}$ & 0,0023 & 0,0002 \\
\hline $10: 30-11: 00$ & 34 & 0,0017 & 0 & 0 & 0 & 0 & 0 & 0 & 0 & 0,0015 \\
\hline $11: 30-12: 00$ & 32 & 0,4586 & 0 & 0,0015 & 0 & 0 & 0 & 0 & 0,0015 & 0,0015 \\
\hline $11: 30-12: 00$ & 34 & 0,0014 & 0 & 0 & 0 & 0 & 0 & 0,0005 & 0,0001 & 0,0015 \\
\hline $12: 30-13: 00$ & 23 & 0,0023 & 0 & 0 & 0 & 0 & 0 & 0,0002 & 0 & 0 \\
\hline $12: 30-13: 00$ & 32 & 0,0012 & 0 & 0 & 0,0006 & 0 & 0 & 0,0003 & 0,0005 & 0,0018 \\
\hline $13: 30-14: 00$ & 21 & 0,0028 & 0 & 0 & 0,0016 & 0 & 0 & 0,0004 & 0 & 0 \\
\hline $13: 30-14: 00$ & 22 & 0,0085 & 0 & 0 & 0,0021 & 0 & 0 & 0,0003 & 0 & 0 \\
\hline $13: 30-14: 00$ & 38 & 0,0028 & 0 & 0 & 0 & 0 & 0 & 0 & 0,0005 & 0,0017 \\
\hline $15: 30-16: 00$ & 23 & 0,0023 & 0 & 0 & 0 & 0 & 0 & 0,0011 & 0 & 0 \\
\hline $16: 30-17: 00$ & 21 & 0,0019 & 0 & 0 & 0 & 0 & 0 & 0 & 0 & 0 \\
\hline
\end{tabular}

Tabela 4c - Como na tabela $12.6 a$, mas para a grade 1. 
correspondência entre observação e simulação, no que se refere à trajetória da pluma. Às 06 UTC a pluma é muito estreita e desloca-se para nordeste acompanhando a direção do vento dentro do vale. Um pequeno erro na reprodução da direção do vento pode produzir erros consistentes no cálculo das concentrações nas primeira horas de emissão. Neste horário as partículas estão em alturas entre 0 e $300 \mathrm{~m}$. Por conservar um núcleo principal compacto, a pluma apresenta puffs esporádicos e isolados de dimensões pequenas e que viajam em várias direções para fora da pluma principal. Às 08 UTC, partes da pluma se desprendem e começam a viajar para oeste e bem a norte do domínio. $O$ deslocamento para oeste está sendo provocado pelo cisalhamento horizontal do vento no vale (nota-se que a velocidade do vento aumenta no centro do vale do Reno), tal que as partículas tendem a deslocarem-se para regiões onde a velocidade do vento é maior. Às 12 UTC a pluma divide-se em duas partes. Uma parte desloca-se para dentro dos vales Kraichgau e Neckar e a outra parte permanece dentro do vale do Reno, próximo a Floresta Negra, parecendo estar estacionada naquela região. Isto pode explicar o valor de concentração elevado observado às 12 UTC no amostrador 32. Neste momento as partículas atingem uma altura de $800 \mathrm{~m}$ acima da superfície. Às 16 UTC uma grande nuvem de partículas cobre totalmente os vales Kraichgau e Neckar e poucas partículas restam próximo ao local de emissão.

A partir das Figuras 9 a-d, nota-se que durante o dia 16/09 existe um transporte de poluentes a partir do vale do Reno para os vales Kraichgau e Neckar. Como já havia sido observado por Löffler-Mang et al. (1998), o deslocamento de ar entre regiões de altas densidades de poluição e industrialização influenciarão fortemente o transporte de poluentes na área do experimento TRACT. Este transporte de poluentes é devido, basicamente, à direção do vento dentro e acima da CLP e aos efeitos orográficos. A 
observação de Löffler-Mang parece ser comprovada pelo trabalho de simulação desenvolvido na presente análise.

\section{CONCLUSÔES}

Os principais objetivos deste estudo eram o de realizar um acoplamento entre os modelos RAMS e SPRAY para simular os processos de transporte e difusão de um poluente liberado durante o experimento TRACT e implementar uma nova parametrização para os parâmetros turbulentos no programa de interface MIRS. De acordo com o que se descreve nos resultados, pode-se afirmar que tais objetivos foram alcançados. Em particular, é mostrado como a conexão entre o RAMS e o SPRAY, através do MIRS, é plenamente funcional e operativa. A partir das simulações com este sistema de modelos é possível descrever algumas considerações finais para resumir os resultados deste estudo:

- a qualidade da simulação obtida com o sistema de modelos RAMSMIRS-SPRAY é muito boa; o modelo reproduz bem o comportamento da pluma do poluente, a distribuição temporal e espacial da concentração e a localização do máximo de concentração;

- a parametrização para todas as estabilidades (Degrazia et al., 2000) apresenta bons resultados, mesmo que a mesma seja válida, em primeira aproximação, somente para terreno plano e não para uma situação de terreno complexo como é o caso da área do experimento TRACT;

- um dos melhores resultados é obtido utilizando a parametrização ECT/RAMS; este fato é importante, pois mostra que a utilização da informação direta do modelo RAMS descreve, com suficiente detalhe e precisão, o campo de concentração no nível da superfície sobre terreno complexo;

- a partir dos resultados para a grade 1 do modelo SPRAY, nota-se que o modelo consegue calcular concentrações significativas durante as 12 
horas de observação, simulando a distribuição dos vários puffs do traçador.

Por fim, este trabalho se mostra útil no sentido que permite demonstrar a praticabilidade da simulação completa de um processo dispersivo (reconstrução do campo de vento, geração do campo de turbulência e reconstrução do campo de concentração) em terreno complexo. Isto vem de encontro com a problemática da poluição do ar e é de importância fundamental para proteção e qualidade do ar no sentido de avaliação do impacto ambiental.

\section{AGRADECIMENTOS}

Nós agradecemos ao Dr. Zimmermann (Karlsruhe, Alemanha) pela assistência com relação aos dados coletados durante o experimento TRACT. Agradecemos ao ENEL (Milano, Itália) por permitir a utilização do modelo SPRAY. Nós agradecemos também à CAPES, ao CNPq. e à FAPERGS, pelo suporte financeiro. 


\section{REFERÊNCIAS BIBLIOGRAFIA}

Anfossi, D., Ferrero, E., Sacchetti, D., e Trini Castelli, S., 1997, Comparison among empirical probability density functions of the vertical velocity in the surface layer based on higher order correlations, Bound.-Layer Meteor. 82:193.

Chiba, O., 1978, J. Meteor. Jpn. 56:149.

Cox, R., Bauer, B.L. e Smith, T. (1998): A mesoscale model intercomparison. Bull. Amer. Meteor. Soc., 79, 265-283.

Degrazia, G.A., Anfossi, D., Carvalho, J.C., Mangia, C., Tirabassi, T., e Campos Velho, H.F., 2000, Turbulence parameterisation for PBL dispersion models in all stability conditions, Atm. Env. (in press).

Ferrero E., e Anfossi D., 1998, Comparison of PDFs, closures schemes and turbulence parameterizations in Lagrangian Stochastic Models, Int. J. Environment and Pollution, 9, 384-410.

Frisch, U. (1995): Turbulence. Cambridge University Press.

Hanna S.R., 1982, Applications in air pollution modeling, Atmospheric Turbulence and Air Pollution Modeling, F.T.M. Nieuwstadt and H. Van Dop eds., Reidel-Dordrecht, Cap. 7.

Kalthoff, N., Binder, H.J., Kossmann, M., Vögtlin, R., Corsmeier, U., Fiedler, F., e Schlager, H., 1998, The temporal evolution and spatial variation of the boundary layer over complex terrain, Atm. Env. 32:1179.

Löffler-Mang, M., Zimmermann, H., e Fiedler, F., 1998, Analysis of ground based operational network data acquired during the september 1992 TRACT campaingn, Atm. Env. 32:1229.

Maryon, R.H., e Buckland, A.T., 1994, Diffusion in a Lagrangian multiple particle model: a sensivity study, Atm. Env. 28:2019

McNider, R.T., e Pielke, R.A., 1994, Diurnal boundary-layer development over sloping terrain, J. Atmos. Sci. 38:2198. 
Mellor, G.L., e Yamada, T., 1982, Development of a turbulence closure model for geophysical fluid problems, Rev. of Geophys. and Space Phys. 20:851.

Pielke R.A., Cotton W.R., Walko R.L., Tremback C.J., Lyons W.A., Grasso L.D., Nicholls M.E., Moran M.D., Wesley D.A., Lee T.J., e Copeland J.H. (1992) "A comprehensive meteorological modeling system - RAMS". Meteorology and Atmospheric Physics, 49, 69

Thomson, D.J., 1987, Criteria for the selection of stochastic models of particle trajectories in turbulent flows, J. Fluid Mech. 180:529.

Tinarelli, G., Anfossi, D., Bider, M., Ferrero, E., e Trini Castelli, S., 2000, A new high performance version of the Lagrangian particle dispersion model SPRAY, some case studies. Air Pollution Modelling and its Applications XIII, S.E. Gryning and E. Batchvarova eds., Plenum Press, New York, in press

Trini Castelli, S., e Anfossi, D., 1997, Intercomparison of 3-D turbulence parameterisations for dispersion models in complex terrain derived from a circulation model, Il Nuovo Cimento 20C:287.

Zimmermann, H., 1995, Field phase report of the TRACT field measurement campaign EUROTRACT report, Garmisch-Partenkirchen. 


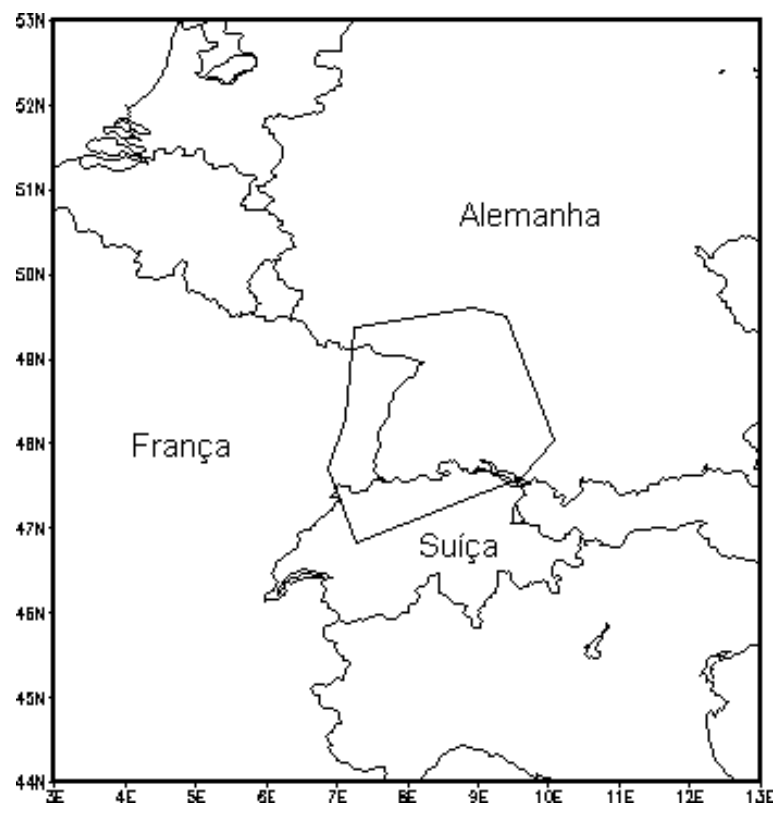

Figura 1 - Área do experimento TRACT. 


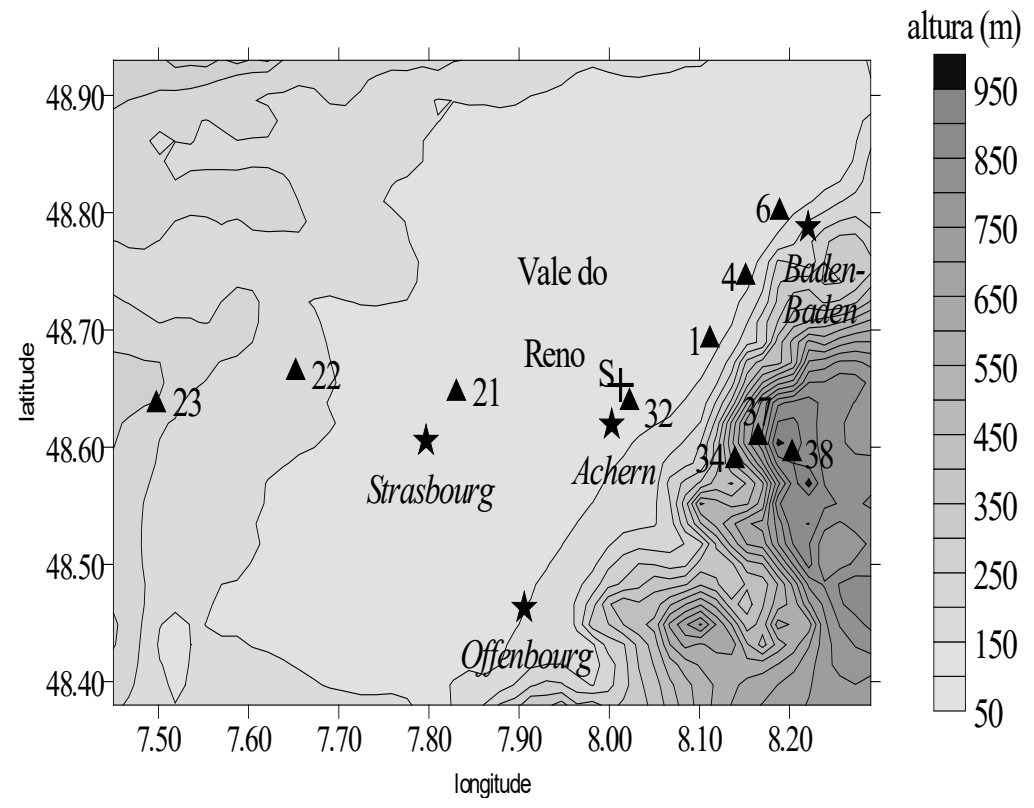

Figura 2 - Localização dos amostradores de concentração (triângulos) e da fonte de emissão (cruz). A figura representa uma área aninhada à área principal do experimento.

36 Rev. Ciência e Natura, Dispersion Process: 9 - 43 , 2000. 


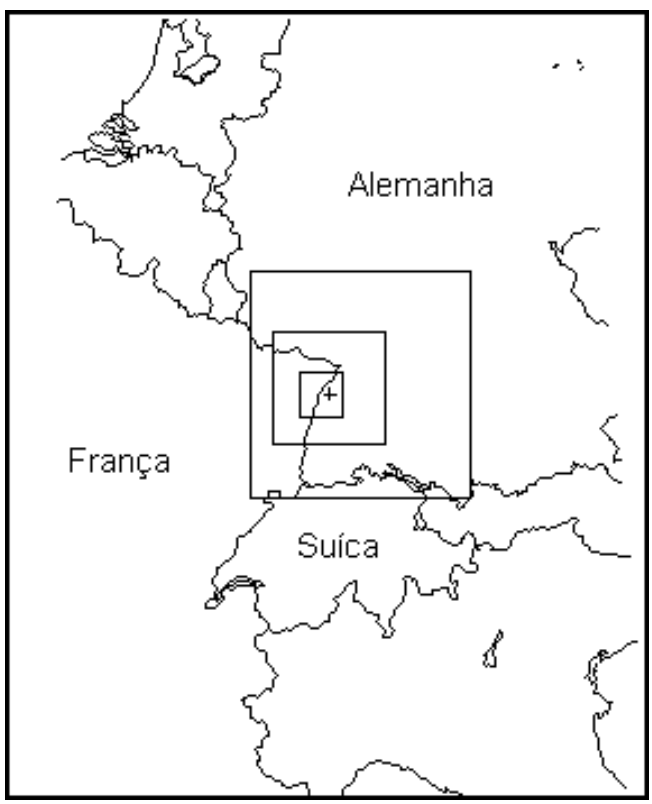

Figura 3 - Domínios de simulação do modelo RAMS. A cruz indica a posição da fonte de emissão. 
a)

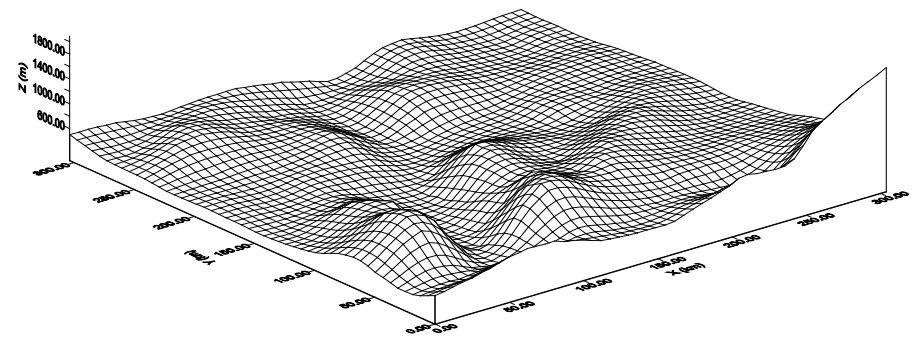

b)

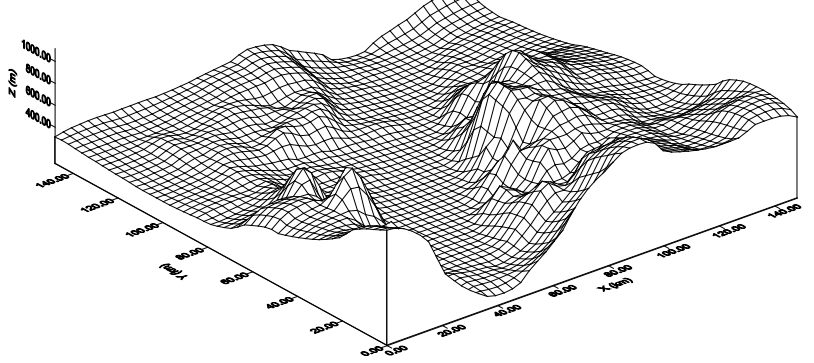

c)

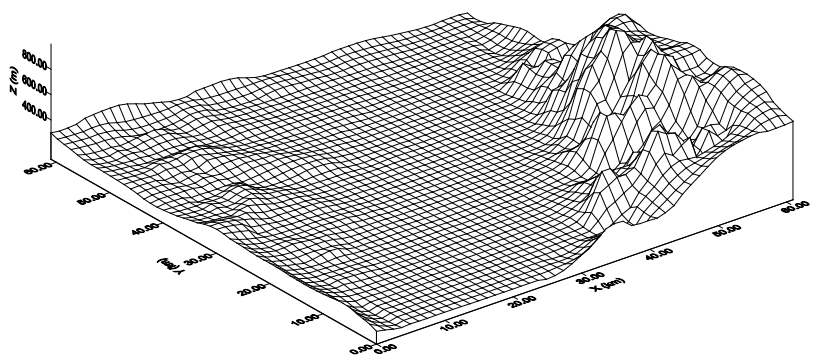

Figura 4 - Orografia: (a) grade 1, (b) grade 2 e (c) grade 3.

38 Rev. Ciência e Natura, Dispersion Process: 9 - 43 , 2000. 


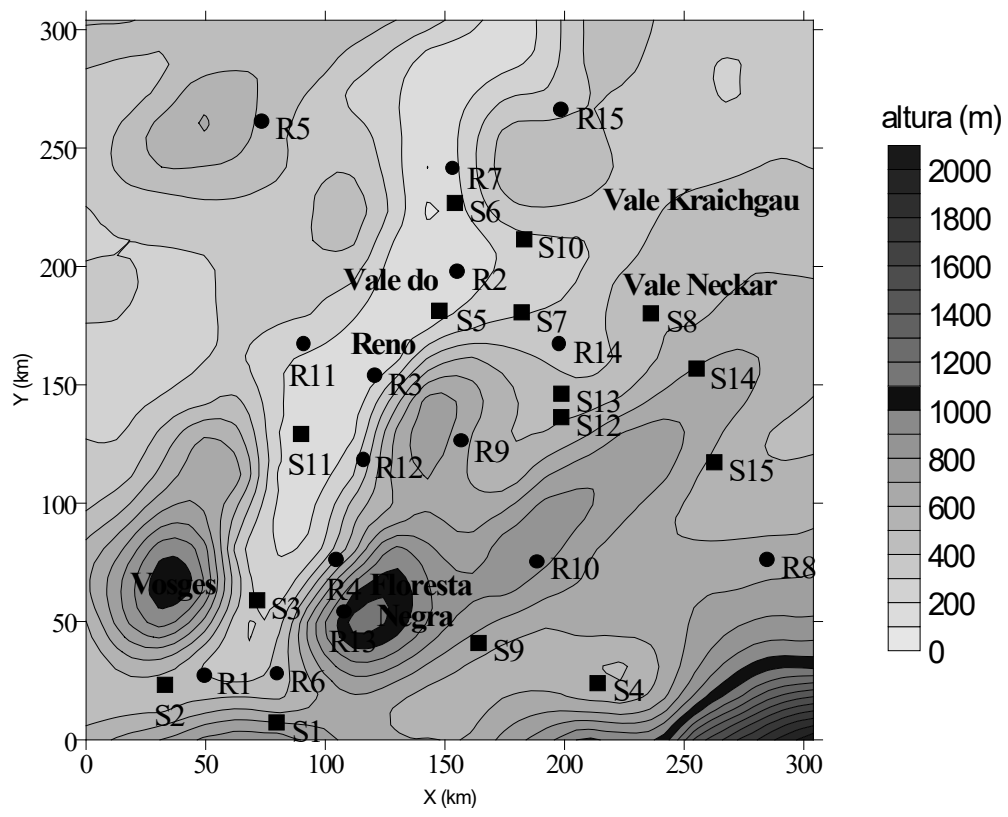

Figura 5 - Localização das estações de superfície e de radiosondagem e principais características orográficas em relação a grade 1 de simulação do RAMS. 

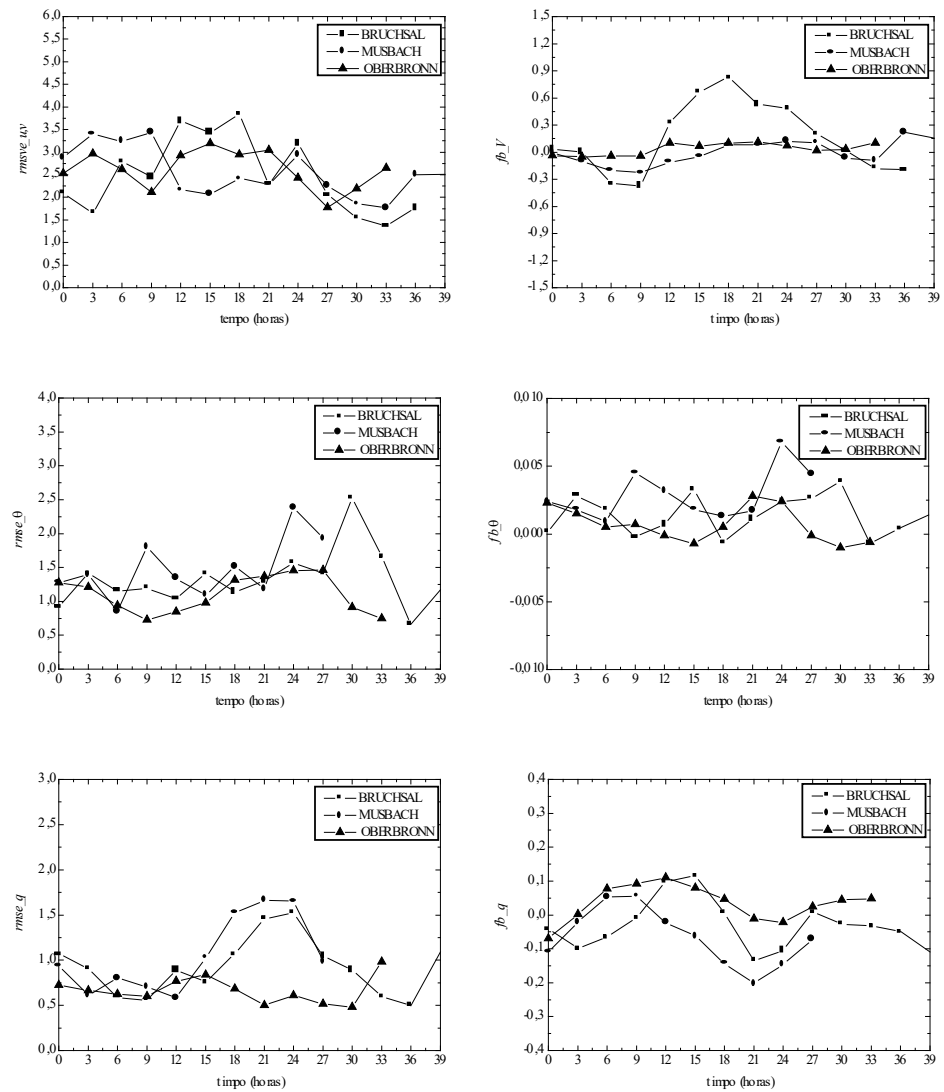

Figura 6 - Evolução no tempo dos índices estatísticos nas estações de radiosondagem Bruchsal, Musbach e Oberbronn. Hora 00 UTC, dia 16/09.

40 Rev. Ciência e Natura, Dispersion Process: 9 - 43 , 2000. 

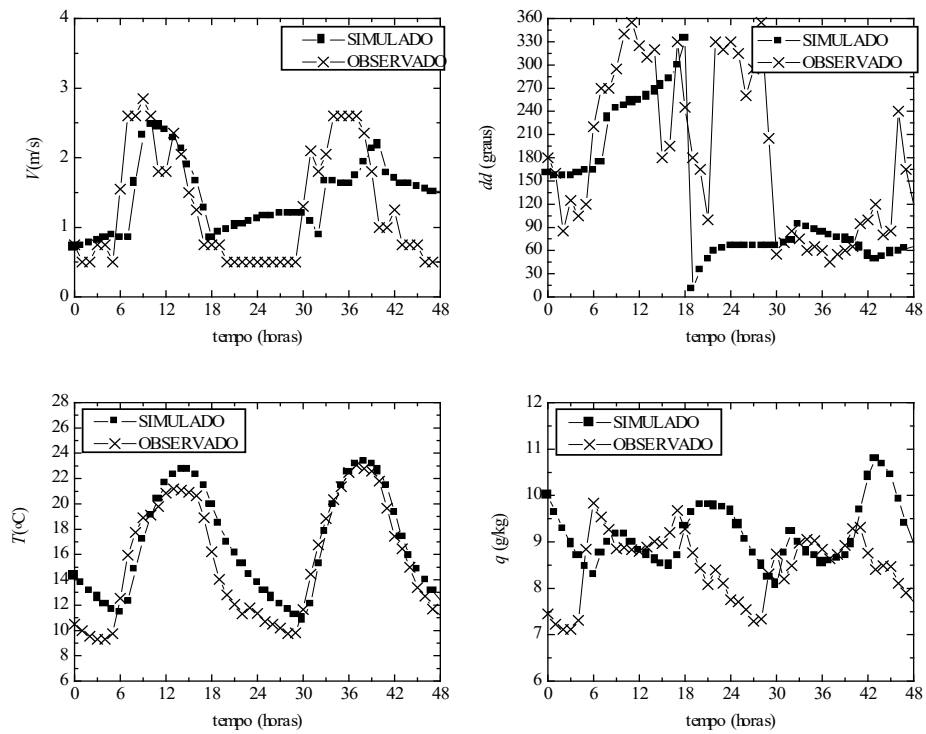

Figura 7 - Evoluções no tempo simuladas e observadas para a localização da estação de superfície Sinsheim. Direções $0^{\circ}$ e $360^{\circ}$ representam a mesma direção. Hora 0 indica 00 UTC, dia 16/09.

Rev. Ciência e Natura, Dispersion Process: 9 - 43 , 2000. 

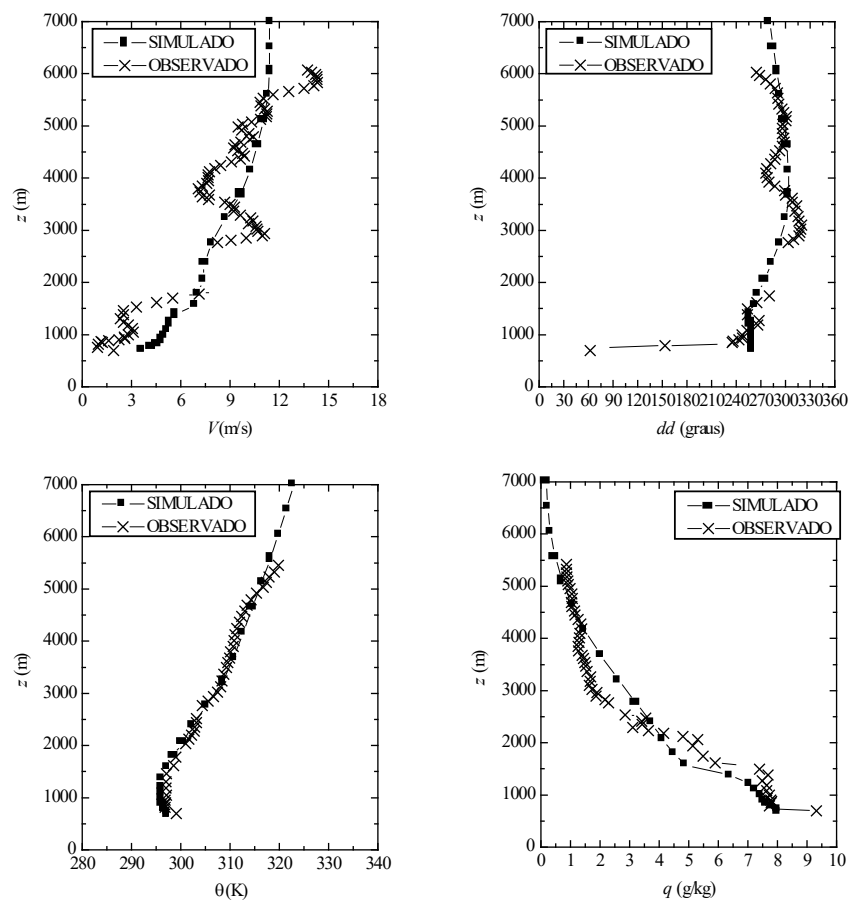

Figura 8 - Perfis simulados e observados na localização da estação de radiosondagem Musbach às 12 UTC em 16/09. Direções do vento $0^{\circ}$ e $360^{\circ}$ representam a mesma direção. 
a)

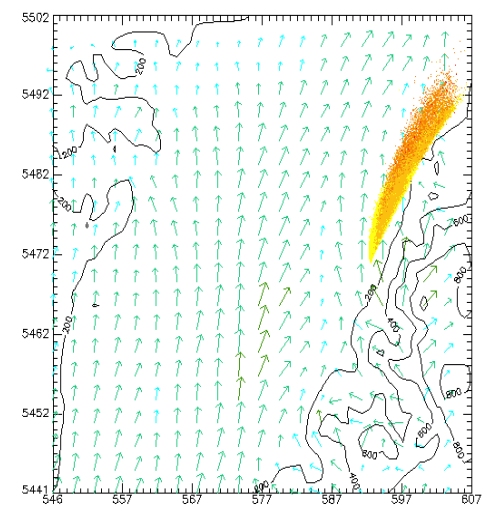

c)

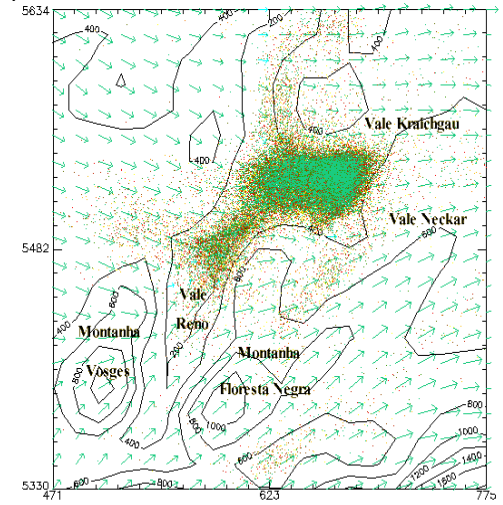

b)

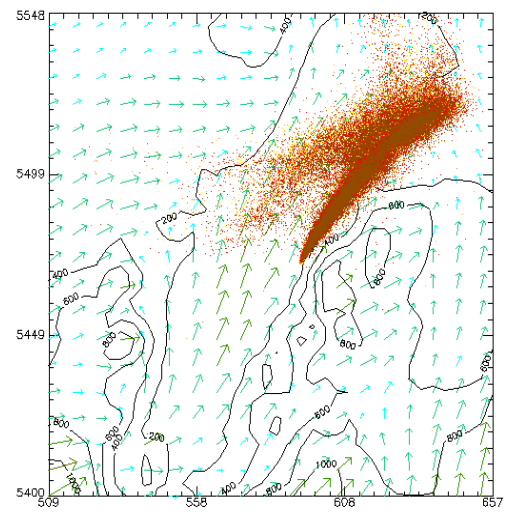

d)

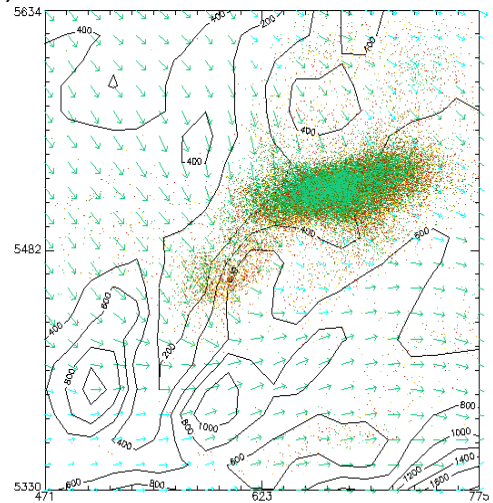

Figura 9 - Posição das partículas e campo de vento em 10 m: (a) grade 3, às 06 UTC; (b) grade 2, às 08 UTC; (c) grade 1, às 12 UTC e (d) grade 1 , às 16 UTC. Os contornos indicam a topografia em metros. 
44 Rev. Ciência e Natura, Dispersion Process: 9 - 43 , 2000. 